\title{
LOCATING MULTILINGUAL LITERACIES: A CASE STUDY OF LITERACY PRACTICES AT THE FATIMA JINNAH WOMEN UNIVERSITY (FJWU), RAWALPINDI
}

\author{
Saima Umer ${ }^{1}$, Sarwet Rasul ${ }^{2}$, Sumaira ${ }^{3}$, Zafar Iqbal ${ }^{* *}$ \\ ${ }^{1,3}$ National University of Modern Languages, Multan Campus, Pakistan; ${ }^{2}$ Fatima Jinnah Women University Rawalpindi, \\ Pakistan; ${ }^{4 *}$ Minhaj University Lahore, Pakistan. \\ Email: *zammad.aslam@gmail.com
}

Article History: Received on $14^{\text {th }}$ May 2021, Revised on $20^{\text {th }}$ June 2021, Published on $24^{\text {th }}$ June 2021

\begin{abstract}
Purpose: The present study attempts to analyze literacy practices of adults with low academic qualifications in their work domain to prove that the traditional definition of literacy as merely an ability to read and write may not prove an effective yardstick in the postmodern digitalized global world.
\end{abstract}

Methods: The research is contextualized in nature and takes place in real-life settings of Pakistani society. The researchers collected the data through semi/non-structured interviews based on a questionnaire consisted of 53 questions, excluding demographic-related details. The duration of the fieldwork was almost one month. During the data collection process, the researcher kept on tailoring the questions to have insights into the LNL practices of adults concerning the aim of the study and the progression of the interviews/conversation.

Main Findings: The study finds multiliteracies in the work domains of sanitary workers in the shape of LNL and technology integration. Sanitary workers seem to utilize less English language vocabulary, specifically naming (nouns), i.e., washroom, cleaners/acids, vacuum cleaner, biometrics, blower, floor machine, or mobile phones. Workers also use diverse literacy practices in their communications, i.e., multilingual lexicon, numeracy, or digital literacies.

Application of the Study: The findings suggest that this workplace multilingualism and multiliteracy practices would help the organizations (public/private) to instruct their employees/staff for purposeful communication(s). Moreover, this study would facilitate the process of training need analysis (TNA) during the trainings as the model of the present research can be adapted by the trainers to assess the literacy level(s) of the trainees for better classifications to provide proper training according to their prior knowledge.

The Originality of the Study: According to the researchers' best knowledge, this type of study appeared not conducted in a specific field in the selected geographical area. Moreover, the research offers a new theoretical framework to conduct a multiliteracy study in sanitary works.

Keywords: Literacy Practices, Work Domain, Multiliteracies, Multilingual Literacy, Literacy Broker.

\section{INTRODUCTION}

In contemporary times, literacy cannot be viewed as a monolithic phenomenon anymore; instead, it refers to a striking range of possibilities extending from school literacy to cultural literacy, computer to moral, and even emotional literacy. Thus, literacy in a simple yet modern sense can be described as a subject that deals with how to live, raise children, and prepare ourselves for the rigors and excitements of the new century (Roser \& Ortiz-Ospina, 2016). The radical and digital transformation of our world from the 1990s onwards has changed the concept of 'literacy, numeracy and language' (LNL), not only in child education but also in adult literacy practices (Umer et. al., 2018). Therefore, a shift from literacy to literacies and rather multiple literacies can be essential to cope with this technologically mediated and postmodern world (Langford, 2021). As part of this global trend or shift, Pakistan, as one of the most linguistically diverse countries in the world having more than 73 languages, has become a hub of multiliteracies, which are both domain-specific and situated in nature (Cope \& Kalantzis, 2013; and Rahman, 2011). The origin of these multiliteracies can also be traced to the country's progressive development in the postmodern hybrid era; and the resultant increase in demand for the use of diverse languages like English/ vernaculars in both the everyday lives and professional environment (Ashraf \& Tsegay, 2016).

In the above context, it becomes essential to understand that although literacy is necessary to our lives, many aspects of what makes us human, including language, intellect, the capacity for social living, and technical resourcefulness, do not rely only upon formal literacy. On the contrary, it is primarily because the 'so-called' illiterate people also use language(s), intellect, the capacity of social living, and technical resourcefulness to survive successfully in this digitized global world (Greenhow \& Lewin, 2016). Therefore, literacy is not a phenomenon only limited or to be used by the academically literate people, as literacy has now assumed diversified dimensions; and "literacy" as a keyword in the current era has the status like that of "science" in the 19th century (Fakhriyah et al., 2017).

Literacy in its postmodern sense refers loosely to any specific body of systematic and valuable knowledge. The label literacy has been extended to areas that have no or little connection to the text. For example, moral literacy does not require reading (Serafini, 2017). This transformation has also impacted the research in literacy as it traditionally included 
dichotomies such as literate vs. non-literate, written vs. spoken, educated vs. uneducated, and modern vs. traditional (Weiland, 2017). The postmodern definition of literacy thus defines it as an activity of social groups and an essential feature of various forms of social organization. Like every other human activity or product, literacy also has social relations embedded within it, and these relations always include the aspects of conflict and cooperation (Leibrandt, 2019). Like language itself, literacy is an exchange between classes, races, or sexes (Ohmann, 1987). Therefore, to view Adult Literacy and Numeracy and Language (ALNL) subsequently, in this postmodern era of diverse or multiple literacies, is not an easy task. People do different things at different points or domains of their lives to cope with the rapidly changing technological world (Tett et al., 2006).

Therefore, the present study intends to utilize ALNL (considers literacy as a highly contextual terminology). It is an emerging field of studies in Pakistan to explore how this concept integrates within the Pakistani culture and society, characterized by diverse linguistics and social backgrounds (Shah \& Ishaque, 2017). Also, it is in this context. This study aims to study how adult workers with low or almost no formal school qualification but having diverse linguistic backgrounds make choices about using language in a particular professional or workplace context. Moreover, this study also aims to identify the rationale and aspirations behind using and choosing a specific language while examining the mechanics of the language shift and multiple literacies amongst these adult workers from a professional or workplace perspective. It is also pertinent to mention that this project does not view literacy as a set of individual skills and competencies alone but as emergent and situated social contexts (Barton and Hamilton, 1998), thereby discarding the functional skill approach. Therefore, this research focuses upon the use, refinement, and diversification of literacies in the job spectrum of sanitary workers (male) at the FJWU, Rawalpindi; and reflects upon the benefits of the use of multiple literacies in both the personal and professional domains (Cope \& Kalantzis, 2013).

\section{Aim \& Objectives of Research}

This research explores multiple/multilingual literacies of the male sanitary workers at FJWU, Rawalpindi, while employing the social practice Approach of ALNL as suggested by Barton and Hamilton (1998). With this aim, the research identifies the following objectives:

- To study why and how the workplace acts as a site for language shift.

- To explore the diverse literacies (multilingual/numeracy/digital) that adults may learn from their work environment and those that their work requires.

- To analyze how adults with less or no school qualifications cope with their job requirements at their workplace in this postmodern multilingual hybrid world of work.

- To determine the extent to which multiple literacy practices operate in work among sanitary workers (male) at their workplace.

\section{Research Questions}

The following main and subsidiary questions have provided the conceptual framework for the study:

\section{- Main Question:}

How does the concept of multiple/multilingual literacies exist in the working environment of adults with less or no school qualification in the Pakistani context?

\section{- Subsidiary Question/s:}

1. What types of multilingual literacy practices are required by the sanitary workers (male) at FJWU, Rawalpindi, to perform their duties effectively?

2. What is the role being played by the English language in their job-specific tasks?

\section{Social Practice Approach}

Barton \& Hamilton (1998) developed the Social Theory while focusing on the importance of Literacy, Numeracy \& Language (LNL) and studied the relationship between them. The Social Practice's view of the literacy practices refers to these as situated literacies (Barton et al., 2000); and views these as local literacies (Barton \& Hamilton, 1998); where both of these are considered specific to contexts that seem intertwined in the social lives of individuals. The main philosophy of the Social Theory approach to ALNL may get understood with the help of six propositions. Each of these propositions can be identified as valuable when talking about adults and education, whether in the context of LNL, diversity, social inclusion, or even the international settings (Luke, 2018). The starting point of this theory is the assertion that 'literacy is a social practice,' which is the main viewpoint and provides a conceptual framework for the approach employing the following propositions (Craig \& Guzmán, 2018):

1. Literacy is social practices that can be inferred from events and mediated by written texts.

2. Literacy practices are domain-specific and vary accordingly. 
3. Social institutions and power relationships influence literacy practices, so some literacies become more dominant, visible, and influential than others.

4. None of the literacy practices are purposeless. Instead, they all may seem embedded in broader social goals and cultural practices/traditions.

5. All kinds of literacy practices are culturally rooted and historically situated.

6. In this fast-changing, fluid global world of digitized information, literacy practices keep changing, and new ones may get acquired through informal learning and sense-making processes.

The practice approach that would categorize the 'new literacy studies' draws mainly upon ideas and methodologies. It may seem distinguished from the more psychological process of socio-historical activity theory. It is rooted in Lev Vygotsky's notions and gives way to the concept of multiliteracies (Cope \& Kalantzis, 2013) to meet the fast-changing needs of this globally digitized world.

\section{Assessment of the ALNL}

Assessing ALNL in the postmodern era, it is essential to view its development while employing a more open and broader concept of the terms than the previously used outdated, narrow and rigid views. This development reflects a shift from a previous autonomous perspective to a modern view of ideological understanding by considering it in the broader context of institutional and power relationships (Green, 2018; Tikly, 2016). This notion of ALNL, as depicted in the Social Practice Approach, reflects a switch from the concept of social exclusion to social inclusion that is developing grounds for introducing social practice approach in comparison to the functional skills approach to assess the ALNL relationship in contemporary times of digitized information. Moreover, this situated approach to ALNL provides a contextualized concept of LLN (Oughton, 2018). According to this approach, literacy and numeracy may seem organized within specific social, emotional, and linguistic contexts, integrating feelings, values, routines, skills, understanding, and activities (Yasukawa et al., 2018).

It is important to note that ALNL shows how the social practice approach to learning and teaching may get developed more inclusive views of adult literacy, numeracy, and language in contemporary times of globalized and digitized information to improve. That is 'Skills for Life' compared to the functional skill approach (Grotlüschen et al., 2019). Olson (2009) points at a broader view of literacy rather than defining it as a mere subject limited to reading and writing. The adults facing problems with reading and writing nevertheless engage in a wide range of literacy activities. Therefore, none of the social theories incorporating literacy as a situated practice is devoid of the intermingling of LNL and technology in the postmodern era (Hamilton, 2016). The integration of LNL, technology, and social context is depicted in Figure 1 below:

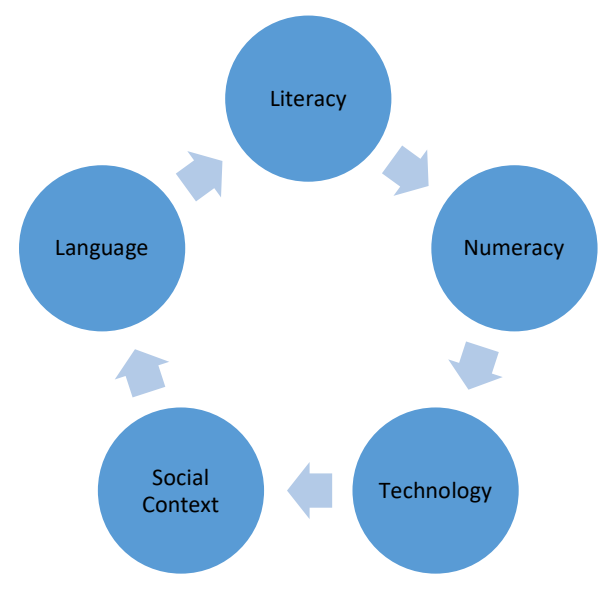

Figure 1: LNL, Technology, and Social Context

Source: Self-made

It is also worth considering that we cannot generalize the findings in different fields of studies as these were limited to space and time; therefore, imposing these upon unrelated cultural areas would not be appropriate (Derrida, 1997). Towards this end, one needs to revisit preceding notions of literacy/literacies, multilingual literacies, numeracy, and language with a postmodern lens of digitized hybridization (Cannon, 2018). Moreover, literacy may not seem based on a predictable destination, yet it evolves to understand the world. Literacy has become a construct, and according to the LNL theorists, the plurality of literacies is necessary because texts can be read in various ways while utilizing a blend of academic and generative skills (Harvard, 2006 as cited in Tett et al., 2006). Gee (2009) sums up the afore-mentioned discussion in these words: 
"Many different social and cultural practices incorporate literacy, therefore, there many different "literacies" (legal literacy, gamer literacy, country music literacy, academic literacy of many different types). People do not just read and write in general; they read and write specific sorts of "texts" in specific ways; these ways are determined by the values and practices of different social and cultural groups (Gee, 2009, p. 11).

\section{The interconnectedness of Literacy Practices and Domains}

Literacy, as mentioned earlier, can be best understood as a set of literacy practices aimed at utilizing written texts which people come across in their daily lives (Barton and Hamilton, 1998). In this context, these practices are also referred to as 'folk models' as these are inclusive of events and ideological preconceptions that underpin them (Street, 1993). However, literacy practices work differently concerning different domains. According to Fishman et al. (2005), domains may get understood as the social context of interaction taking place in people's daily lives and distinctive types; and can be referred to as an intricate network of literacy practices wired together (Bennett et al., 2018). Domains in terms of literacy practices vary on a continuum from more formally structured (family, education, religion, government, and administration) to less formally structured (friendship, shopping, and casual conversation) (de Pourbaix, 2005). Domains may also get understood as an instrument of achieving social compatibility as to be successful in this postmodern world of diverse needs and demands, all members of a society need to wear an appropriate mask or face according to the requirements of a specific domain; while projecting literacy practices associated with this domain (Esposito, Kebede \& Maddox, 2015). For instance, attending a funeral ceremony varies completely in its social demands and nature from attending a wedding ceremony; therefore, literacy practices associated with these domains vary. According to Holmes (2008), there are four major domains of language use, which are distinctive in demands concerning their addressee, setting, and topic of conversation (Figure 2).

\begin{tabular}{llll}
\multicolumn{2}{c}{ Domains of language use } \\
Domain & Addressee & Setting & Topic \\
\hline Family & Parent & Home & Planning a family party \\
Religion & Priest & Church & Choosing the Sunday liturgy \\
Education & Teacher & School & Solving a maths problem \\
Employment & Employer & Workplace & Applying for a promotion \\
& &
\end{tabular}

Figure 2: Domains of Language Use

\section{Source: http://www.ello.uos.de/field.php/Sociolinguistics/Domain}

\section{The distinction between Social Practice and Functional Skill Approaches}

As already discussed, the Social Practice Approach to LNL views literacy as an integral part of contemporary life in one way or another, primarily because we live in a textually mediated world. It shifts the focus from a narrow, functional, and externally limited definition of LNL learning to more open and diverse definitions that focus on what people do with their knowledge, understanding, and skills in various contexts. It employs LNL practices embedded in different events, which are taking place in different domains of life varied in nature (Kral, 2012). In this way, it develops a literacy thesis (general to specific) to set grounds for the Social Practice Approach to aid teaching and learning environments concerning ALNL in contemporary times. This social theory of LNL focuses on learning literacy beyond school to bridge the gap perpetuated due to inequality and social divisions, to investigate how social inequalities affect LNL opportunities for people belonging to different social classes, ages, genders, and genders, ethnicities et cetera (Perry, 2012).

Learning and teaching as integral and central elements of LNL in Social Practice Theory aim to design an ' $\boldsymbol{a}$ fit for purpose' course embedded in a particular context to discard social exclusion by minimizing social inequality and class difference. The theory discusses the role of multi/literacies in the formation of class, gender, and ethnic identities while challenging previous definitions of the key terminologies and providing a broader view concerning postmodernism (McHale, 2012). Therefore, literacy learning that draws on a social practice approach 'works' in policy terms and addresses socio-cultural inequalities by devising a 'learning infrastructure' promotes 'generative skills' relevant to people's lives and needs (Purcell-Gates, 2020). The social practice approach is successful as learning depends on solid social relationships between learners and teachers.

On the contrary, the functional skill model of literacy studies is a de-contextualized theory, as it does not incorporate the context and needs of the community as essential components of literacy practices (Luke, 2012). This theory views skill 
as individuals' possession and aims at designing policies related to literacy accordingly. In other words, this theory considers literacy as an individual phenomenon and not grounded or situated in nature (Scherer et al., 2019).

The main differences between the Social Practice approach and the Functional Skill Model of LNL are as follows: (see Tett et al. 2006 for more details):

\section{Skill Approach}

- Social Exclusion

- De-contextualized

- Individual View

- Individual's Resource

- 'I' centered

\section{Social Practice View}

Social Inclusion

Contextualized

Holistic View

Collective Resource

'We' Centered.

Overall, the socio-cultural or Social Practice theory has the necessary theoretical scope and explanatory power to provide a rich in detailed insight with a holistic view to interpret ideological underpinnings concerning power relations; while employing multimodality to draw valid, authentic, unprejudiced, and reliable findings (Black et al., 2013). Therefore, it is more suitable as a theoretical framework in terms of analyzing multiliteracies and multilingualism in the daily lives of a community embedded in a specific social setup as it provides more inclusive views of adult literacy, numeracy, and language in contemporary times of globalized and digitized information to improve 'Skills for Life' while focusing upon the weak areas (Barton and Hamilton, 1998).

\section{CONCEPTUAL /THEORETICAL FRAMEWORK}

This research analyses the ALNL in the Pakistani context. Hence, the research model adopted here is that of the 'Social Practices Approach' with a view of local literacies of working class as suggested by Barton and Hamilton (1998), i.e., considering LNL as a collective resource and not as individuals' property. The research framework is significant as it helps locate literacies from the local perspectives or how people make sense of their lives through their everyday literacy practices. Moreover, how vernacular literacies, which are often hidden literacies, are in use at different domains of life (work, education et cetera), and how literacy, education, and quality of local life are interlinked (Barton \& Hamilton, 1998).

The present research is a case study focusing upon the adult male sanitary workers at FJWU, Rawalpindi, to explore the integration of LNL practices and the implications of multilingualism in their personal and professional lives. The focus seems based upon the reason that literacies as 'Situated Social Practices' highlight and explain the situated social nature of (multi) literacies by focusing on the things common people do in their daily lives (Barton et al., 2000).

The Social Practice Approach, as one of the ethnographic methods to measure ALNL is the only means for finding out what literacy is in a specific context and how this literacy can be validly measured (Szwed, 1981). Szwed (1981) believes that ethnographic methods, means to analyze ALNL, can be best understood from three social practice models as Barton and Hamilton (1998) provided, Heath and Finnegan, and Street; all these three models deal with literacy in action. Moreover, as these models also consider what we can accomplish with the use of scripts and texts, these shift emphasis from the consequences of literacy for society to the study of its uses by individuals and its functions in particular groups; primarily because these models view literacy not as an advance over oral use of language but as complementary to it (Duckworth \& Ade-Ojo, 2015).

The above view suggests that the 'Social Practice View' of ALNL is indeed a sound and practical theory for the present research as it offers a distinct perspective from the functional skills approach; while providing a contextualized concept of literacy rather than literacies, from reading to understanding the digital information (Bhatt, 2012; Baig, et al., 2019). It also reflects the diversity of literacies, numeracies, and languages in people's everyday lives by covering all possible domains from home to work et cetera, focusing upon the lives of adults mainly (Tett et al., 2006).

\section{RESEARCH METHODOLOGY}

The present research is mainly qualitative. It takes place in natural settings to identify the variables or factors that account for the multilingual/multiple literacy practices among the male sanitary workers at FJWU, Rawalpindi. However, quantification also validates the findings of qualitative analysis by providing 'stories with numbers' (Tett et al., 2006). Quantitative and qualitative research paradigms are a more powerful way of informing policy if they work together to create 'stories with numbers' rather than working separately.

\section{Sample}

The researcher has purposively selected ten adult male sanitary workers at FJWU, Rawalpindi, for data collection for the study to analyze the needs that force or urge the adults to be multilingual/multiple literates. FJWU is one of the most diverse universities in caste/ethnicity, language, and culture. There are students and workers from diverse linguistic, 
cultural, and religious backgrounds. Thus, ten male sanitary workers of diverse linguistic and regional backgrounds selected as a source of data collection for the present study, whose details are as follows:

- Age Bracket: 25 years to 40 years

- Experience: One year to 11 years

- Education: None to Matric

- All were married and had children

- Diverse linguistic/regional backgrounds

- Scale: 1 or 2

- Strata: Lower Working Class

\section{Tools of Data Collection}

The researchers collected the data through semi/non-structured interviews based on a questionnaire consisted of 53 questions, excluding demographic-related details. The duration of the fieldwork was almost one month (10 April 202015 May 2020). During the data collection process, the researcher kept on tailoring the questions to have insights into the LNL practices of adults concerning the aim of the study and the progression of the interviews/conversation.

\section{Classification of Questions}

- Total questions - 53 (Excluding demographics)

- Questions related to language/s practices - 22

- Question-related to digital literacy - 15

- Questions related to Numeracy practices - 8

- Questions related to literacy practices - 11 (general/social practices)

\section{Pilot Study}

Initially, the researchers conducted a pilot study to determine the feasibility of data and refine the scope of the study. The pilot study findings provided positive grounds for the study to be carried out in the context of a Pakistani diverse, multilingual society.

\section{Ethical Considerations}

All the semi/non-structured interviews have conducted with the respondents' willingness and due permission of their managers/supervisors.

\section{ANALYSIS \& DISCUSSION}

This section analyses the data collected through semi-structured interviews from male sanitary workers at FJWU, Rawalpindi. It locates how LNL and technology are integrated with their daily lives, especially at their work domains the Social Practice Approach to measure ALNL as situated practices. A detailed description of the data analysis at word/phrase level, thematic level, and discourse (interview) level have been followed by incorporating the methodology suggested by Barton and Hamilton (1998). The analysis has been conducted keeping in view the concept of multiliteracies, hence employing the following themes for ease in understanding (these themes emerged during data analysis).

1. Contextualizing Literacy Practices of Sanitary Workers in Pakistan

2. Academic literacy

3. Multilingual Literacy - Use of Code-Mixing

4. Numerated Expressions

5. LNL Integration

6. Digital Literacy

7. Concept of Literacy Broker

8. Point of Disparity / Lack of Internal Consistency

\section{Contextualizing Literacy Practices of Sanitary Workers in Pakistan}

If the traditional yardstick of literacy as an ability to read and write only is applied to measure the ratio of literacy of the 
sanitary workers (male), except 2, all of them were found illiterate. However, if the Pakistani concept of literacy that is 'one who can sign is literate' is utilized, they all were found literate as all of them could sign their name in Urdu/English to mark their attendance on the register. Except for two (who matriculated), all were middle or without any formal school education. However, as they work in a hybrid culture, they are all able to speak more than two languages; able to use digital types of equipment (biometrics, vacuum cleaner, mobile, floor machine, blowers); and were also found unconsciously integrating LNL in their professional and personal lives on daily basis.

\section{Academic literacy}

The findings with regards to academic literacy in Table 1 below:

Table 1: Academic Literacy

\begin{tabular}{ccccc}
\hline No Education & Below Primary & Primary & Middle & Matric \\
\hline 2 & 3 & 1 & 2 & 2 \\
\hline
\end{tabular}

Source: Self-made

It is pertinent to mention that out of all the research subjects, only three were able to read Urdu, and three were able to read and write in Urdu, while two were able to read and write both in Urdu and English languages, they were Matriculate.

\section{Multilingual Literacies}

There were 53 questions (excluding demographics) asked from the research subjects during informal interviews. Out of these, 20 questions were about the language/s they knew and spoke competently. The data confirms that they all were multilingual speakers and could speak more than two languages competently. Punjabi and Urdu were the languages mainly used in their work domain; as with colleagues, their language of communication was Punjabi, whereas, with their manager / senior designation, they used the Urdu language. The subjects learned languages (Punjabi /Urdu) by using their observational and listening skills. As the nature of their job did not require the use of English, therefore, none of them could speak English fluently; while only two were able to speak very few basic English phrases/sentences, e.g., thank you, please sit, please take tea, my name is et cetera, but they did understand the English language. The Punjabi language was like a lingua franca (also known as bridge/link language) for them as it is not their mother tongue or native language (Brosch, 2015). They all belonged to diverse linguistic and geographical backgrounds working as sanitary workers at FJWU, Rawalpindi. At home, their language of choice was their mother tongue or Punjabi language.

Moreover, one participant (uneducated) was a competent speaker of 4 languages (Punjabi, Urdu, Potohari, and Pushto). Though he understood English, he could not speak it properly. The only one knew two languages (Urdu/Punjabi), while the rest were multilingual. As far as attendance marking was concerned, three marked their attendance in English, while the rest used Urdu for this purpose. Only one could read and write in any three languages (Punjabi, Potohari, and Urdu) except English, while two could read and write in English. Five participants could only understand English to some extent but could not read or write in it. Three participants could not even understand, read and write in English (though they were using English words in their Urdu conversation during the interview sessions). Four participants admitted to reading novels, magazines, and Islamic literature in Urdu. Only three could put their signatures in Urdu but could not read and write in any language. Interestingly, none of them could read/write in their native/mother tongue except for one.

\section{Ratio of Code-Mixing in their Language Use}

During data analysis, it seemed that the participants could do occasional code-switching by using English vocabulary items in their Urdu conversation without knowing it. When asked if they could speak and understand English, most of them replied negatively but did admit to understanding English to a minimal extent. However, when asked about their job description, all of them described their designation as 'sanitary worker,' and none of them called themselves a 'sweeper or jamadar.' Sanitary worker is an English language word, and they were using this very casually as if it was an Urdu language word. Similarly, the participants also used many English language words during their interviews, e.g., biometrics, ATM, mobile, vacuum cleaner, floor machine, bike, metro, education, et cetera. However, when they inquired about the person who helped them in opening accounts or using ATM at the bank, they gave the same answer: ' madam at the bank.'

\section{Numerated Expressions}

The data confirm that all participants could calculate money, salaries, and leaves with ease in Urdu / Punjabi languages. Two could also calculate by employing the English numerical system. However, except for one, none of them was able to do calculations in their mother tongues. Two were able to write checks themselves, while the rest took help from seniors, in-charge, or the bank staff for writing checks at the start of the month. One could use ATM and be also able to change passwords, check the account balance, and could withdraw cash.

\section{Digital Literacy}

The findings from the interviews indicated that all the participants were able to use digital types of equipment like 
vacuum cleaners, blowers, and floor machines for cleaning as sanitary workers and biometrics to mark their attendance digitally. However, in case of any problem with machines, they could not do anything except inform their seniors/ incharge. They all also knew how to use a biometric machine to mark their attendance digitally. All of them knew how to drive a bike though only 3 had personal motorbikes. One out of 10 also knew car driving and wanted to attend a vocational course on 'driving' to improve his skill further. One participant had an ATM card and knew how to operate it. Initially, the bank staff taught him how to use an ATM card, but he became competent enough to use it himself properly. Three participants were found to be regular users of Whatsapp and Facebook and had 'digital identities. Another did not know how to operate Facebook and did not have any digital identity, but he kept on liking and forwarding different posts to others without knowing the actual content (as he was uneducated at all in terms of academic literacy) on his colleague's FB account. One participant had no mobile at all, while another had a non-smart mobile phone. The remaining seven had smartphones, and they knew how to use them for saving contacts by names and for receiving/making calls, and reading text messages. Some of them had passwords on their phones as well.

\section{Concept of Literacy Broker}

The findings from the interviews also confirmed that the concept of 'literacy broker,' as mentioned by Collins and Blot (2003), also existed among the sanitary workers at FJWU, Rawalpindi. The participants admitted that once they joined the institute, they were not aware of using digital equipment for cleaning (vacuum cleaners, blowers, and floor machines), marking attendance (biometrics), ATM for drawing cash, and smartphones. However, their seniors/ in-charge and the bank staff acted as literacy brokers by teaching them how to use this digital equipment properly and effectively. Therefore, the concept of a literacy broker or a source of help seemed present among the research participants because of their professional needs and problems and academic literacy constraints.

\section{Point of Disparity / Lack of Internal Consistency}

When asked about studying/education (vocational/academic), one 40 years old participant stated that there was no specific age to study. On the other hand, when asked if he would like to attend any course/s if offered at the workplace, the participant declared that in his case, the appropriate age to study had passed. Another participant stated that neither had any aspirations for studying nor he had any use for it. However, it is pertinent to note that the same participant expressed an interest in attending a course on 'how to use FB .' He also used his colleagues' FB pages on his smartphone. It reflected a lack of internal consistency on behalf of the respondent (Kruger, 2000).

\section{Major Findings}

Following are the significant findings from this research:

- The study confirms that multiliteracies (Cope \& Kalantzis, 2009) are significantly at play in the work domains of sanitary workers in the shape of $\mathbf{L N L}$ and technology integration.

- The findings indicate that sanitary workers' nature requires significantly less use of English language except for naming/ identifying certain items (washroom cleaners/acids) or equipment (vacuum cleaner, biometrics, blower, floor machine, mobile phones). Therefore, they do not need to use it as a medium of conversation or understanding in their daily personal or professional lives.

- It has also been found that the sanitary workers learned diverse literacy practices (multilingual, numeracy / digital literacies) either by observation or with the help of peers/seniors/bank staff, all of whom act as 'Literacy Brokers' (Collins \& Blot, 2003).

- Code-mixing (Hymes, 1986) between Urdu and English is a common phenomenon among sanitary workers.

- It has also been found that the sanitary workers are literate enough (though not academically) to cope with their work domain's requirements effectively in contemporary times. Their literacy practices vary based on different factors like socio-economic, education, and job designation. The sanitary workers (male), though they belonged to different cities of Pakistan, were all living in Rawalpindi for employment purposes. To survive successfully in a digitally urbanized city of Pakistan, they needed to be multi-literate not in terms of being multilingual but also in terms of being digitally and numerically literate.

- All the sanitary workers were found well-aware of whom to consult and how to solve their problems with the help of others as mediators (Eve \& Ann, 2002).

\section{CONCLUSION}

Overall, this study demonstrates that language use and choices are necessary to understand within the specific domains of their relevance; instead of blanket assertions of language as 'a right' or language as 'an opportunity for social mobility. Integration of LNL is now a commonly occurring phenomenon and cannot be separated from each other as there are literacies within numeracy and vice versa. Moreover, LNL is a highly contextual phenomenon as it varies from culture to culture and domain to domain and, accordingly, literacy practices. Hence, literacy is a relative term that remains in kaleidoscopic flux. Therefore, providing an absolute definition of this term is impossible in this postmodern 
era where the traditional notion as a yardstick to define literacy may not work. Literacy also plays a vital role in asserting identities and demarcating individuals/societies under the influence of factors like power, age, gender, religion, socioeconomic status, politics, geography, and time. In short, literacy practices seem intricately wed, and people intrinsically shape literacy practices based upon the demands of their daily lives embedded in a social setup.

\section{LIMITATIONS AND SUGGESTIONS FOR FUTURE RESEARCH}

The present study explores the literacy practices only in the geographical area of Rawalpindi. The research appeared to restrict to collect the data only from one institute. The financial support for traveling to other areas was not available. Therefore, the researchers collected the data from a specific area. The conceptual framework, research design, and theoretical framework would seem helpful for future research at a broader level involving more institutions or organizations where the same type of participants work.

\section{ACKNOWLEDGEMENT}

Financial support from any corner is not involved.

\section{AUTHORS CONTRIBUTION}

Saima Umer: Devised the research idea, started the paper, and finished working on each part.

Dr. Sarwet Rasul: Devised the theoretical framework and extracted the theoretical data.

Sumaira: Worked on data scrutinization and raw interpretations.

Zafar Iqbal: Devised the research design, editing, and copyediting.

\section{REFERENCES}

1. Ashraf, M. A., \& Tsegay, S. M. (2016). Analysis of globalization and Englishization in Pakistan. International Journal of Research Studies in Language Learning, 5(1), 79-88. https://doi.org/10.5861/ijrsll.2015.1205

2. Bailey, B. (2000). Language and negotiation of racial/ethnic identity among Dominican Americans. Language in Society, 29, 555-582. https://doi.org/10.1017/S0047404500004036

3. Barton, D. and Hamilton, M. (1998). Local literacies: Reading and writing in one community. Routledge: England.

4. Barton, D., Hamilton, M., IvaniÚc, R., \& Ivanič, R. (Eds.). (2000). Situated literacies: Reading and writing in context. Psychology Press.

5. Baig, F. Z., Yousaf, W., Aazam, F., Shamshad, S., Fida, I \& Aslam, M. Z. (2019). Power, Ideology and Identity in Digital Literacy: A Sociolinguistic Study. International Journal of English Linguistics, 9(2). p. 252-264. https://doi.org/10.5539/ijel.v9n4p252

6. Bennett, S. V., Gunn, A. A., Gayle-Evans, G., Barrera, E. S., \& Leung, C. B. (2018). Culturally responsive literacy practices in an early childhood community. Early Childhood Education Journal, 46(2), 241-248. https://doi.org/10.1007/s10643-017-0839-9

7. Bhatt, I. (2012). Digital literacy practices and their layered multiplicity. Educational Media International, 49(4), 289-301. https://doi.org/10.1080/09523987.2012.741199

8. Black, S., Balatti, J., \& Falk, I. (2013). Health literacy and social capital: what role for adult literacy partnerships and pedagogy? Studies in Continuing Education,35(2), 146-164. https://doi.org/10.1080/ $\underline{0158037 X .2012 .712038}$

9. Brosch, C. (2015). On the Conceptual History of the Term Lingua Franca. Apples - Journal of Applied Language Studies. Centre for Applied Language Studies, University of Jyväskylä, 9(1), 71-85. https://doi.org/10.1080/0158037X.2012.712038

10. Cannon, M. (2018). Digital media in education: Teaching, learning and literacy practices with young learners. Springer.

11. Collins, J. And Bolt, R. (2003). Literacy and literacies: Texts, power, and identity. Cambridge: Cambridge University Press. https://doi.org/10.1017/CBO9780511486661

12. Cope, B., \& Kalantzis, M. (2013). Multiliteracies: New literacies, new learning. In Framing Languages and Literacies (pp. 115-145). Routledge. https://doi.org/10.4324/9780203070895-13

13. Craig, J., \& Guzmán, L. (2018). Six Propositions of a Social Theory of Numeracy: Interpreting an Influential Theory of Literacy. Numeracy: Advancing Education in Quantitative Literacy, 11(2), 1-24. https://doi.org/1 $\underline{0.5038 / 1936-4660.11 .2 .2}$

14. De Pourbaix, R. (2005). Emergent literacy practices in an electronic community. In Situated literacies (pp. 141164). Routledge.

15. Derrida, J. (1997). Of grammatology. Baltimore: The Johns Hopkins University Press.

16. Duckworth, V., \& Ade-Ojo, G. (2015). Adult literacy policy and practice: From intrinsic values to instrumentalism. Springer.

17. Ennser-Kananen, J. (2014). The right to be multilingual: How two trilingual students construct their linguistic legitimacy in a German classroom. The Graduate School of Minnesota: USA. 
18. Esposito, L., Kebede, B., \& Maddox, B. (2015). The value of literacy practices. Compare A Journal of Comparative and International Education, 45(3), 363-380. https://doi.org/10.1080/03057925.2013.862019

19. Eve, G. and Ann, W. (2000). City literacies: Reading Across Generations and Cultures. Routledge, New York.

20. Fakhriyah, F., Masfuah, S., Roysa, M., Rusilowati, A., \& Rahayu, E. S. (2017). Student's Science Literacy in the Aspect of Content Science? Jurnal Pendidikan IPA Indonesia,6(1), 122870. https://doi.org/10.152 94/jpii.v6i1.7245

21. Fishman, J., Lunsford, A., McGregor, B., \& Otuteye, M. (2005). Performing Writing, Performing Literacy. College Composition and Communication, 57(2), 224-252.

22. Gee, J. P. (2009). New digital media and learning as an emerging area and worked examples as one way forward (p. 92). The MIT Press. https://doi.org/10.7551/mitpress/8563.001.0001

23. Green, B. (2018). Literacy studies and curriculum theorizing; or, the insistence of the letter. In The insistence of the letter (pp. 195-225). Routledge. https://doi.org/10.4324/9780429454486-12

24. Greenhow, C., \& Lewin, C. (2016). Social media and education: Reconceptualizing the boundaries of formal and informal learning. Learning, media, and technology, 41(1), 6-30. https://doi.org/10.1080/17439 $\underline{884.2015 .1064954}$

25. Grotlüschen, A., Thériault, V., Nienkemper, B. \& Capstick, T. (2019). Critical viewpoints on adult literacy practices at the time of PIAAC. International Journal of Lifelong Education, 38(4), 361-365. https://doi.org/10.1080/02601370.2019.1614105

26. Hamilton, M. (2016). Imagining literacy: A sociomaterial approach. In Beyond economic interests (pp. 1-17). Brill Sense. https://doi.org/10.1007/978-94-6300-444-2_1

27. Heath, S. B. (1977). Social history. Bilingual education: Current perspectives, 1, 53-72.

28. Heller, M. (1995). Language choice, social institutions, and symbolic domination, Language in Society, 24(3), 373-405. https://doi.org/10.1017/S0047404500018807

29. Heller, M. (2006). Linguistic minorities and modernity: A sociolinguistic ethnography. 2nd ed. New York: Continuum.

30. Holmes, J. (2008). An introduction to sociolinguistics (3rd ed.). Harlow et al.: Longman, ch. 2.

31. Hymes, D. (1986). Directions in sociolinguistic: The ethnography of communication. Oxford: Blackwell.

32. Kadel, S. (2018). Language choice and use in multilingual contexts of Nepal: an ethnographic study (Doctoral dissertation). Jawaharlal Nehru University, New Delhi, India.

33. Kral, I. (2012). Talk, text, and technology: Literacy and social practice in a remote Indigenous community (Vol. 14). Multilingual Matters. https://doi.org/10.21832/9781847697608

34. Kruger, R.A. (2000). Designing and conducting focus group interviews. Minesota: SAGE

35. Langford, L. (2021). Information literacy: Seeking clarification. In IASL Annual Conference Proceedings (pp. 195-205). https://doi.org/10.29173/ias18127

36. Leibrandt, I. M. (2019). Postmodern Literacy: Multimodal, Hypertextual, Intertextual Reading. In Teaching Literature and Language Through Multimodal Texts (pp. 258-276). IGI Global. https://doi.org/10.4018/978-15225-5796-8.ch014

37. Luke, A. (2012). Critical literacy: Foundational notes. Theory into Practice, 51(1), 4-11. https://doi.org/10. 1080/00405841.2012.636324

38. Luke, A. (2018). The social construction of literacy in the primary school. Routledge. https://doi.org/10.4324/ 9781315100951-2

39. McHale, B. (2012). Constructing postmodernism. Routledge. https://doi.org/10.4324/9780203388594

40. Ohmann, R. (1987). Politics of letters. Wesleyan University Press.

41. Olson, D. R. (2009). Education and literacy. Infancia y aprendizaje, 32(2), 141-151. https://doi.org/10.1174/ $\underline{021037009788001824}$

42. Ouane, A. (2003). Towards a multilingual culture of education. UNESCO Institute for Education, Hamburg: Germany.

43. Oughton, H. (2018). Disrupting Dominant Discourses: A (Re) Introduction to Social Practice Theories of Adult Numeracy. Numeracy: Advancing Education in Quantitative Literacy, 11(1), 1-18. https://doi.org/10.5038 /1936-4660.11.1.2

44. Pahl, K. (2004). American Anthropological Association, University of Sheffield, United Kingdom.

45. Perry, K. H. (2012). What Is Literacy? A Critical Overview of Socio-cultural Perspectives. Journal of Language and Literacy Education, 8(1), 50-71.

46. Purcell-Gates, V. (Ed.). (2020). Cultural practices of literacy: Case studies of language, literacy, social practice, and power. Routledge. https://doi.org/10.4324/9781003064374

47. Rahman, T. (2011). From Hindi to Urdu: A Social and Political History. Karachi: Oxford University Press.

48. Roser, M. and Ortiz-Ospina, E. (2016). Literacy. Published online at OurWorldInData.org. Retrieved from: https://ourworldindata.org/literacy

49. Scherer, R., Siddiq, F., \& Tondeur, J. (2019). The technology acceptance model (TAM): A meta-analytic structural equation modeling approach explaining teachers' adoption of digital technology in education. Computers \& Education, 128, 13-35. https://doi.org/10.1016/j.compedu.2018.09.009 
50. Serafini, F. (2017). Visual literacy. In Oxford Research Encyclopedia of Education. https://doi.org/10.1093/acr efore/9780190264093.013.19

51. Shah, S. J., \& Ishaque, W. (2017). Challenges of national integration in Pakistan and strategic response. ISSRA PAPERS, 9(2), 35-48.

52. Street, B. V. (1993). The new literacy studies, guest editorial. Journal of research in reading, 16(2), 81-97. https://doi.org/10.1111/j.1467-9817.1993.tb00039.x

53. Szwed, J. (1981). The ethnography of literacy. Writing: The nature, development, and teaching of written communication, 1, 13-23.

54. Tett, L., Hamilton, M. Hillier, Y. (2006). Adult literacy, numeracy and languages. New York: OUP.

55. Tikly, L. (2016). Language-in-education policy in low-income, postcolonial contexts: Towards a social justice approach. Comparative Education, 52(3), 408-425. https://doi.org/10.1080/03050068.2016.1185272

56. Turner, R. (2014). The 'literacy' idea. Assessment GEMs no.5. Melbourne: ACER.

57. Umer, S., Aslam, M. Z. and Aslam, T. (2018). Literacy and Numeracy Practices in Education: Perspectives and Prospects. The European Journal of Literature and Linguistics, 2, 20-22. https://doi.org/10.29013/EJLL-18-220-22

58. Weiland, T. (2017). Problematizing statistical literacy: An intersection of critical and statistical literacies. Educational Studies in Mathematics, 96(1), 33-47. https://doi.org/10.1007/s10649-017-9764-5

59. Yasukawa, K., Jackson, K., Kane, P., \& Coben, D. (2018). Mapping the terrain of social practice perspectives of numeracy. In Numeracy as Social Practice (pp. 3-17). Routledge. https://doi.org/10.4324/9781315269474-1 